\title{
A educação com enfoque cts no quadro das tendências de pesquisa em ensino de ciências: algumas reflexões sobre o contexto brasileiro atual
}

Silmara Alessi Guebur Roehrig

Sérgio Camargo

\begin{abstract}
Resumo
Este trabalho apresenta reflexões sobre como a Educação com enfoque CTS - Ciência/Tecnologia/Sociedade - tem evoluído no quadro das tendências de pesquisa em Ensino de Ciências no Brasil. Após caracteriza-la a partir de autores como Ziman (1980), Aikenhead (1994) e Yager (1996) buscou-se trazer quais as tendências de pesquisa em Educação no Brasil a partir da década de 1980, de modo a compreender como estas influenciaram a pesquisa no Ensino em Ciências até os dias atuais. Neste momento, as contribuições de Libâneo (1983) e Saviani (1994) são apresentadas, a fim de constituírem o ponto de partida da discussão. Em seguida são apontados trabalhos de pesquisadores da área de Ensino de Ciências, que abordam determinadas tendências nas duas últimas décadas do século passado; destacamos Carvalho e Vannucchi (1996), Teixeira (2003) e Moreira (2000). Na última etapa, autores que trabalharam especificamente com a perspectiva CTS são citados. Percebemos que o enfoque CTS para o ensino de ciências começa a configurar uma tendência de pesquisa no âmbito acadêmico brasileiro apenas a partir do final do século passado, apesar de se tratar de um movimento já consolidado em países da Europa e nos EUA. Há no entanto evidências de pesquisadores brasileiros que já sugeriam o trabalho com elementos que remetem à Educação CTS na década de 1980, como Krasilchik (1987). Por fim, questionamos até que ponto o impacto e a presença dessas tendências nas salas de aula é representativo no contexto brasileiro, apesar de alguns documentos curriculares nacionais já terem incorporado elementos dessa perspectiva.
\end{abstract}

Palavras-chave: Educação CTS, tendências pedagógicas, Ensino de Ciências

Abstract

This paper presents some reflections about how STS Education has been growing in Brazilian Science Education research trends framework. After describing STS Education since authors like Ziman (1980), Aikenhead (1994) and Yager (1996), Brazilian Education research trends are shown in order to discuss how they influenced Science Teaching research from 1980 years to now; for this purpose, contributions of Libâneo (1983) and Saviani (1994) are presented. Next we point few works of Science Teaching researchers which focus was on the trends present on last two decades: Carvalho and Vannucchi (1996), Teixeira (2003) and Moreira (2000). Finally, STS Education Brazilian researches are brought. Therefore, we realize that STS Education in Science Teaching starts to turn into a trend only from the end of last century, despite of being yet a consolidated movement in country such as USA and in Europe. However, we found some evidences that Brazilian researchers had tried to suggest an STS perspective work in the 1980's, such as Krasilchik (1987). After that, we argue if the presence of this research trend is representative in Brazilian classrooms, even though STS contents 
are incorporated in national curriculum parameter documents.

Key words: STS Education, pedagogical tendencies, Science Teaching.

\section{Introdução}

A intenção de superar a forma tradicional de ensinar ciências, pautada na lógica interna da disciplina e que privilegia a visão clássica da ciência, começa a aparecer em pesquisas na década de 1970, inicialmente na Europa e posteriormente com maior força nos EUA. A origem de tais discussões é atribuída em geral aos questionamentos acerca da visão deformada que se tinha da ciência, que era vista como uma atividade autônoma, neutra e isolada de outros contextos, bem como a atribuição de algumas consequências de seu mau uso em determinadas tecnologias. O denominado Movimento CTS - sigla para Ciência, Tecnologia e Sociedade - surge num contexto em que questões acerca de tais consequências ganham força e passa a se exigir maior atenção às atitudes com relação à ciência e tecnologia.

O Ensino de Ciências foi diretamente afetado por tais mudanças, pois é no âmbito escolar que se perpetuam ideias que favorecem a visão deformada da atividade científica. Na década de 1970 ocorrem mudanças importantes na ênfase da educação científica, até então focada na visão do cientista, para um ensino CTS, voltado para a formação do cidadão. Um dos organismos que impulsionam tais mudanças nesse período é a UNESCO - United Nations Educational, Scientific and Cultural Organization - que passa a recomendar, entre outros, a inclusão de elementos que favoreçam a reflexão escolar sobre a contribuição da ciência para nossa herança cultural (SANTOS, M. E., 2001).

Desde essa época até os dias de hoje, passados cerca de quarenta anos, muito foi dito, escrito e discutido acerca deste assunto, de modo que um vasto número de obras relacionadas a Educação CTS foram produzidas e estão disponíveis tanto em meio impresso como eletrônico, a maioria na língua inglesa e espanhola. O que se observa no entanto, é a timidez com que esse movimento atinge o contexto educacional brasileiro. Não me refiro aqui ao meio acadêmico, pois como aponta Santos (2011), pesquisas mostram um crescimento significativo nessa linha de pesquisa nas últimas décadas. O que não se percebe ainda é o impacto na sala de aula, no que concerne à priorização das discussões sobre as relações entre ciência, tecnologia e sociedade com o intuito de formar cidadãos que sejam capazes de estabelecer tais relações no seu cotidiano, independente de sua trajetória acadêmica posterior.

A seguir, após discutir de forma mais adequada o que se entende hoje por Educação CTS, serão identificados trabalhos de pesquisadores brasileiros que de alguma forma se referem à essa abordagem, e de que modo o fizeram. Na sequencia, pretendo fazer algumas considerações, baseadas tanto no estudo da literatura como na minha experiência como estudante de mestrado e professora de Física no Ensino Médio. 


\section{Educação cts}

A compreensão da ciência enquanto campo de produção de conhecimento, até meados do século XX, estava fortemente ancorada no positivismo lógico, corrente filosófica que considera o método científico o principal elemento propulsor do progresso da ciência. Nessa perspectiva, de modo geral, entendia-se a ciência como atividade autônoma, neutra, desinteressada e de caráter cumulativo, entre outros aspectos, de modo que a sua finalidade exclusiva era a busca da verdade, independentemente de fatores externos ao campo científico.

A tecnologia, por sua vez, era vista como a aplicação de teorias científicas, sem, no entanto haver vínculo direto entre as duas áreas. Sendo a ciência uma atividade neutra, qualquer responsabilidade sobre a sua aplicação em tecnologia viria a recair sobre aqueles que dela fizessem uso, ou seja, a responsabilidade sobre questões éticas, políticas e sociais decorrentes do mau uso de determinadas tecnologias não recaiam sobre os cientistas e engenheiros, e sim a quem as consumia.

O questionamento dessas concepções, entre outros fatores, acabou culminando no surgimento de movimentos sociais e políticos, que reivindicavam a tomada de consciência e maior participação dos cidadãos nas decisões que envolvem ciência e tecnologia. $O$ hoje conhecido como Movimento CTS, influenciou reformas educacionais a partir da década de 1970, principalmente na Europa e nos EUA. Basicamente, são dois os campos que abarcam pesquisadores desse movimento: os Estudos CTS, focado nas questões internas das relações CTS no âmbito acadêmico, e a Educação CTS, voltada para o ensino de ciências e sua repercussão no contexto social, uma vez que os estudantes são os futuros agentes decisores da sociedade.

Ziman (1980), a quem se atribui a criação da sigla CTS ${ }^{1}$, argumenta que o foco do Ensino de Ciências convencional é ensinar a ciência 'válida' (valid science), que é aquela produzida dentro dos padrões estabelecidos pela comunidade científica. Nesse âmbito, fatores externos não são considerados, e o contexto social e político não entram em pauta. Para o autor, a intenção principal é treinar futuros cientistas, já que se priorizam os conteúdos que envolvem o estudo do conhecimento acumulado ao longo das gerações de pesquisadores de uma determinada área. Destaca ainda que "toda a instrução formal relaciona categorias e esquemas teóricos derivados do núcleo duro e validados pela pesquisa, sem fazer referência a confusões, complexidades ou à completa ignorância sobre o mundo real" (ZIMAN, 1980, p. 29, trad. nossa).

O autor ainda chama a atenção para o fato de haver "pouca referência às necessidades da maioria dos alunos que não irão, de fato, seguir carreira de cientista" (ZIMAN, 1980, p. 29, trad. nossa). Defende que é urgente que se ensine mais sobre ciência nas escolas, de modo que os

\footnotetext{
${ }^{1} \mathrm{Na}$ introdução de sua obra, Ziman (1980) lista uma série de nomes comumente usados para referenciar tal assunto; decide então usar a sigla STS, para Science, Technology and Society, com o intuito de simplificar tal referência
}

R. B. E. C. T., vol 6, núm. 2, mai-ago.2013 ISSN - 1982-873X 
alunos "olhem para dentro da caixa preta que envolve a ciência" (ibidem, p. 53). Ressalta ainda. que o principal objetivo da Educação CTS não é substituir a educação científica convencional nem modificá-la totalmente, mas sim corrigir esse preconceito inconsciente, a partir do trabalho com temas complementares que envolvam as relações entre ciência, tecnologia e sociedade.

Além de lamentar que o ensino de ciências seja em geral associado à preparação para o ensino superior, Yager (1996) apresenta vários argumentos que vão ao encontro das ideias até agora expostas. Afirma que "CTS significa focar nas necessidades pessoais dos estudantes, quais sejam, conceitos científicos e habilidades que sejam úteis no seu cotidiano" (YAGER, 1996, p. 7, trad. nossa). Essa visão é um tanto diferente, segundo o autor, da presente no período pósSputnik, quando era dada ênfase na identificação de conceitos centrais e nas teorias das várias disciplinas científicas. Acreditava-se que a ciência pareceria tão interessante para os alunos quanto o é para os cientistas, se fosse apresentada do ponto de vista deste profissional. 0 problema é que, nessa concepção, não há espaço para a perspectiva do aluno, uma vez que the é atribuída a condição de enxergar o mundo a partir da visão do cientista.

Com relação à utilidade e ao significado da ciência para o aluno, Yager (1996, p. 17) argumenta, citando resultados de pesquisas, que a maioria dos adultos ao olhar para traz e lembrar-se de sua experiência na ciência escolar, apresenta uma visão negativa desta, não encontrando significado ou utilidade para aqueles conceitos estudados no seu cotidiano. Além disso, a ciência aprendida na escola parece não ser internalizada pelo aluno; pesquisas conduzidas por psicólogos cognitivistas (CHAMPAGNE \& KLOPFER, apud YAGER, 1996) mostram que a maioria dos alunos que concluem o ensino médio (high school) apresentam concepções ingênuas e equivocadas sobre o mundo real, por serem incapazes de estabelecer relações entre os conceitos estudados e os fenômenos ou acontecimentos que ocorrem ao seu redor. Tais argumentos reforçam a ideia da necessidade de mudanças radicais no ensino de ciências; nesse sentido, a perspectiva da Educação CTS parece fornecer subsídios no mínimo interessantes para uma efetiva reformulação curricular.

É preciso, no entanto, salientar que há muitas formas de definir o que é Educação CTS. Aikenhead (1994) pretende esclarecer algumas imprecisões sobre essa temática, separando-a em dois componentes: o instrucional, que abrange os métodos e estratégias para uma prática efetiva sob esse enfoque, e o curricular, explorando quatro aspectos: função, conteúdo, estrutura e sequência.

Quanto à função do currículo CTS, o autor destaca que este é orientado no aluno, ao invés de ser orientado no cientista, como ocorre no currículo tradicional. Para o autor, ensinar ciência a partir da perspectiva CTS significa "ensinar sobre os fenômenos naturais de maneira que a ciência esteja embutida no ambiente social e tecnológico do aluno" (AIKENHEAD, 1994, p. 48, trad. nossa). Isso porque no currículo tradicional, o conteúdo de ciências é ensinado de forma isolada da tecnologia e sociedade. Num currículo CTS, o conteúdo da ciência é conectado e integrado ao 
cotidiano do aluno, indo ao encontro de sua tendência nata de associar a compreensão pessoal de seu ambiente social, tecnológico e natural, passando a encontrar sentido na ciência em suas experiências diárias.

Um dos objetivos do ensino CTS é reverter à visão negativa que se tem das ciências, com o intuito de instigar o interesse pelos assuntos científicos, "particularmente pelos alunos brilhantes e criativos que são muitas vezes desencorajados por um currículo tedioso e irrelevante" (AIKENHEAD, 1994, p. 49, trad. nossa). Além disso, a responsabilidade social na tomada de decisões em assuntos que envolvem ciência e tecnologia figura entre as prioridades do currículo CTS, já que cada vez mais o cotidiano das pessoas é modelado de acordo com o surgimento de novas tecnologias. A alfabetização científica, segundo o autor, define também um grupo de objetivos, apesar de considerá-lo mais um elemento de persuasão, já que dificilmente alguém se posicionaria contra a alfabetização científica dos cidadãos.

Contudo, o ensino CTS não ignora a função do currículo tradicional, que é preparar o aluno para as próximas etapas na educação ou para "ensinar respostas certas": apenas dá menor ênfase a esse fator, privilegiando a formação tanto de futuros cientistas ou engenheiros, como a de cidadãos intelectualmente capazes de participar de forma ativa em processos decisórios em sua comunidade.

Com relação ao conteúdo num curso CTS, Aikenhead (1994) afirma que para o ensino médio (high school), ao contrário do ensino superior em que os alunos lidam com questões mais abstratas, as experiências concretas dos estudantes ocupam posição central no trabalho. Nessa perspectiva, os aspectos humanos e sociais das ciências são abordados de forma simples, porém "intelectualmente honesta". Devem ser abordados, simultaneamente, conteúdos científicos e as relações CTS, de modo que haja interação entre ciência e tecnologia, ciência e sociedade ou tecnologia e sociedade, além de considerar aspectos históricos, filosóficos ou epistemológicos que porventura influenciam essas comunidades.

Os três autores aqui citados, Ziman (1980), Aikenhead (1994) e Yager (1996), além de oferecerem um grande aporte teórico sobre Educação CTS, relatam, eventualmente, experiências bem sucedidas em seus países ${ }^{2}$, de modo que se tem a impressão de que a superação da forma tradicional de ensinar ciências já se consolidou nesses territórios, tendo em vista o ano de publicação destas obras. Não podemos fazer inferências sobre essa questão, já que não temos acesso direto à realidade educacional desses países. Mas o que podemos inferir sobre a realidade da educação científica no Brasil? Como a Educação CTS se configura nesse contexto? É uma tendência ou um modismo passageiro? (AULER, 2011, p. 89). Buscaremos em seguida, relacionar alguns trabalhos de pesquisadores brasileiros que de alguma forma mencionam essa perspectiva como tendência para a reestruturação do Ensino de Ciências no Brasil.

${ }^{2}$ Inglaterra, EUA e Canadá, respectivamente.

R. B. E. C. T., vol 6, núm. 2, mai-ago.2013 ISSN - 1982-873X 


\section{Tendências de pesquisa em educação no Brasil - breve histórico}

Começaremos destacando as tendências pedagógicas para a Educação de um modo mais amplo, a partir das reflexões de Libâneo (1983) e Saviani (1994), e posteriormente avançaremos para produções que enfatizam a Educação CTS como tendência. Trabalho semelhante foi desenvolvido por Teixeira (2003), que faz uma discussão interessante sobre as tendências do ponto de vista desses autores. Nosso objetivo, no entanto é estabelecer relações mais diretas com a Educação CTS, bem como apontar outros trabalhos significativos dentro das tendências.

Com relação às tendências pedagógicas na prática escolar, Libâneo (1983) coloca a questão da formação inicial do professor, o qual é submetido à concepções pedagógicas que priorizam "teorias de aprendizagem ou de ensino que quase nunca têm correspondência com as situações concretas de sala de aula" (p. 11). Para dar suporte a seus argumentos, destaca que:

Em artigo publicado em 1981, Saviani descreveu com muita propriedade certas confusões que se emaranham na cabeça de professores. Após caracterizar a pedagogia tradicional e a pedagogia nova, indica o aparecimento, mais recente, da tendência tecnicista e das teorias crítico-reprodutivistas, todas incidindo sobre o professor (LIBÂNEO, 1983, p. 11).

Cabe aqui descrever melhor essas classificações, a partir de um trabalho mais recente de Saviani (1994). Esse autor divide as teorias pedagógicas em dois grupos: teorias não-críticas e teorias crítico-reprodutivistas. No grupo das teorias não-críticas figuram a pedagogia tradicional, a pedagogia nova e a pedagogia tecnicista, que possuem como denominador comum o fato de encararem a educação como autônoma, buscando compreende-la a partir dela mesma, ou seja, a partir de sua lógica interna. Já as teorias crítico-reprodutivistas buscam compreender a educação a partir de seus condicionantes objetivos ou determinantes sociais, além de entender "que a função básica da educação é a reprodução da sociedade" (SAVIANI, 1994, p. 17). Configuram esse grupo: a) teoria do sistema de ensino enquanto violência simbólica; b) teoria de escola enquanto aparelho ideológico de Estado; c) teoria da escola dualista. Vale ressaltar que o autor assume que as teorias do último grupo não contêm uma proposta pedagógica, uma vez que sua principal função é "explicar o mecanismo de funcionamento da escola tal como está constituída" (ibidem, p. 40).

Nesse mesmo viés, Libâneo (1983) discute as tendências pedagógicas a partir de uma classificação que leva em conta as finalidades sociais da escola. São duas as tendências pedagógicas na perspectiva do autor: a pedagogia liberal, que é uma manifestação da sociedade de classes, em que o papel da escola é preparar os indivíduos para o desempenho de papéis sociais, e a pedagogia progressista, que "partindo de uma análise crítica das realidades sociais, sustentam implicitamente as finalidades sócio-políticas da educação" (LIBÂNEO, 1983, p. 12). 
Cada uma dessas tendências possui correntes distintas, nas quais o autor de debruça a estabelecer para cada uma delas, qual o papel da escola, os conteúdos, os métodos, a relação professor aluno, os pressupostos de aprendizagem e a manifestação na prática escolar. Essas correntes são: pedagogia liberal: a) conservadora, b) renovada progressivista, c) renovada nãodiretiva; pedagogia progressista: a) libertadora, b) libertária e c) de conteúdos.

Libâneo (1983) se posiciona a favor da pedagogia dos conteúdos, ou a Pedagogia CríticoSocial dos Conteúdos (TEIXEIRA, 2003, p. 93), uma vez que considera que o domínio dos conteúdos, métodos e habilidades de raciocínio científico podem conduzir o aluno à formação de uma consciência crítica, de modo que possa atuar na sociedade, transformando-a. Já Saviani (1994) se coloca a favor de uma teoria crítica, que não seja reprodutivista e que seja formulada do ponto de vista dos dominados. Essa concepção foi formulada pelo autor em 1979 e é conhecida como Pedagogia Histórico-Crítica (TEIXEIRA, 2003, p. 92).

Com relação a essas duas correntes, concordamos que

[...] há praticamente uma identidade entre a Pedagogia Crítico-Social dos Conteúdos e a Pedagogia Histórico-Crítica formulada por Saviani. Na verdade, o próprio Libâneo já esclareceu dúvidas em relação às possivveis diferenças entre as duas denominações. Para ele, não há diferenças, e sim convergências entre essas correntes (TEIXEIRA, 2003, p. 93)

Em suma, podemos perceber que as teorias da educação de cunho progressista têm a preocupação com a articulação com o social, a fim de mudar o nível de consciência da classe popular, de modo que o aluno se torne um ser ativo e participante. A Pedagogia Histórico-Crítica é uma concepção bastante cara a alguns documentos curriculares de nível estadual que sofreram reestruturação recente (ex.: $\mathrm{DCE} / \mathrm{PR}, \mathrm{PC} / \mathrm{SC}^{3}$ ), de modo que professores de todas as disciplinas são "convidados" a trabalhar sob essa perspectiva. No entanto, a impressão que se tem é que ainda parece haver um grande distanciamento entre o que os documentos curriculares apregoam e a realidade em sala de aula, de modo que muitos aspectos inerentes à pedagogia tradicional ainda estão presentes no contexto educacional.

\section{Educação cts como tendência de pesquisa no brasil}

As teorias apresentadas não abordaram de maneira específica o ensino de Ciências, tampouco fazem referência a elementos da Educação CTS em si. Há, no entanto, quem faça aproximações entre Educação CTS e a Pedagogia Histórico-Crítica, como Messores (2009), que estabelece relações entre as duas correntes na $\mathrm{PC} / \mathrm{SC}$ para os primeiros anos do ensino fundamental, ou mesmo o artigo de Teixeira (2003), já bastante citado aqui; mas estes são trabalhos bastante recentes e acredito ser interessante iniciar com pesquisas que remontam a

\footnotetext{
${ }^{3}$ DCE/PR: Diretriz Curricular do Estado do Paraná; PC/SC: Proposta Curricular de Santa Catarina.
}

R. B. E. C. T., vol 6, núm. 2, mai-ago.2013 ISSN - 1982-873X 
década de 1980. Aikenhead e Solomon (1994), na introdução de sua obra, reconhecem que a publicação de um livro sobre Educação CTS já era por eles cogitada desde meados da década anterior, mas concluíram na época que era ainda "muito cedo". Se o campo não tinha maturidade suficiente para a publicação de um trabalho mais sólido, conduzido por autores consagrados, para atingir realidades como dos EUA ou Europa, o que dizer da realidade brasileira na década de 1980 ?

Teixeira (2003) identifica alguns autores que apontam tendências para o Ensino de Ciências para a década de 1980. De acordo com o autor, além do ensino tradicional e o método da redescoberta, que já configuravam linhas bastante exploradas, novas propostas como a incorporação do cotidiano dos alunos, a importância dos conhecimentos prévios, interdisciplinaridade e educação ambiental começam a ganhar espaço nesse período.

Outra classificação considerada pelo autor foi feita por Krasilchik (apud TEIXEIRA, 2003, p. 95), que apresenta dois momentos diferentes, sendo o primeiro relativo às correntes teóricas que influenciaram os processos educacionais nos últimos tempos - comportamentalismo, cognitivismo, construtivismo e tendência sócio-cultural -, e o segundo referente às concepções de currículo, que são três: racionalista acadêmica, cognitivista e sócio-reconstrucionista. Segundo o autor, é consenso que o construtivismo vem sendo "a principal corrente teórica sobre o qual se desenvolveram inúmeros trabalhos na área da pesquisa didática nos últimos 30 anos" (TEIXEIRA, 2003, p. 95)

É possível perceber esse aspecto em trabalhos da década de 1990, como em Carvalho e Vanucchi (1996), que afirmam que

\section{"[...] as tendências educacionais que influenciam o ensino continuam sendo preponderantemente construtivistas, mas um construtivismo que concede uma importância considerável ao aprendizado de determinados conteúdos especificos e destaca a influência educativa do professor como um dos fatores determinantes para que a atividade construtiva do aluno se oriente em uma ou outra direção" (CARVALHO; VANUCCHI, 1996, p. 5).}

Como resultado de um levantamento feito em atas de simpósios nacionais e internacionais ocorridos na primeira metade da década de 1990, Carvalho e Vanucchi (1996) apontam para uma mudança na visão da ciência, de modo que essa passa a ser concebida como um conhecimento socialmente elaborado, o que implica perceber que o cientista e o conhecimento por ele produzido "estão igualmente sujeitos a diferentes visões e valores e devemos então nos sentir mais envolvidos e responsáveis pelas decisões que são tomadas" (CARVALHO; VANUCCHI, 1996, p. 17). No entanto, as autoras apontam que a metodologia recomendada "é uma metodologia baseada em pressupostos cognitivistas, sendo a resolução de problemas a atividade preferencial" (ibidem). Ou seja, ao mesmo tempo em que as pesquisas 
apontam que a ciência seja trabalhada de maneira crítica, a influência preponderante no ensino continua sendo o construtivismo, com foco nos conteúdos, bem como a metodologia, que permanece àquela que já há algum tempo vem não correspondendo às expectativas dos educadores.

Para se ter uma visão mais ampla das tendências nas últimas décadas do século $X X$, recorremos a Moreira (2000), que apresenta uma síntese das pesquisas, mais especificamente para o caso da Física:

A questão da aprendizagem nos leva a outro paradigma, o da pesquisa em ensino de Física, que começou a emergir com mais clareza nos anos setenta, com o estudo das chamadas concepções alternativas, consolidou se na década de oitenta, com as pesquisas sobre a mudança conceitual, e encontra-se em plena "ciência normal", neste fim de século, com investigações bastante diversificadas, incluindo, por exemplo, resolução de problemas, representações mentais dos alunos, concepções epistemológicas dos professores e formação inicial e permanente de professores (MOREIRA, 2000, p. 95)

A essa altura, podemos afirmar que a Educação CTS, ou elementos que remetam a ela, não figuram entre as tendências de pesquisa em ensino de ciências até esse período. Moreira (2000) faz uma breve alusão à iniciativas de algumas vertentes, como "Física do cotidiano", "equipamento de baixo custo", "ciência, tecnologia e sociedade", "história e Filosofia da ciência" e, recentemente, "Física Contemporânea" e "novas tecnologias" (p. 95, grifo nosso). Ou seja, as relações entre ciência, tecnologia e sociedade são pouco enfatizadas nas pesquisas até então, não chegando a configurar uma tendência. Vale ressaltar que o autor reconhece o valor dessas iniciativas, mas também considera que há limitações, que podem prejudicar o ensino de Física. Em sua opinião, "é um erro ensinar Física sob um único enfoque, por mais atraente e moderno que seja" (MOREIRA, 2000, p. 95)

No entanto, encontramos uma referência relativamente antiga a elementos da Educação CTS em uma obra de grande relevância para o ensino de Ciências no Brasil: O Professor e o Currículo das Ciências, de Myrian Krasilchik, publicado em 1987. Ao discutir medidas para melhorar o ensino de ciências, Krasilchik (1987, p. 62) apresenta resultados de uma pesquisa feita com professores, com o intuito de detectar quais os elementos que limitam a qualidade do trabalho docente. Destaca, como fatores primordiais dessa limitação, a preparação dos docentes e suas condições de trabalho.

Em seguida, a autora destaca duas tendências no ensino de ciências: ênfase nos trabalhos práticos com o intuito de diminuir a memorização, e a relevância dos conteúdos e sua adequação à idade dos alunos. Segundo a autora, "promover o encontro dessas duas tendências resultará em progresso real do ensino das Ciências" (KRASILSHIK, 1987, p. 67), pois o levaria a atender aos 
objetivos gerais dessa atividade. Dentre os sete objetivos enumerados pela autora, pelo menos seis deles relacionam elementos que remetem diretamente à Educação CTS. O quinto objetivo, transcrito a seguir, é o que melhor representa tal abordagem:

Analisar as implicações sociais do desenvolvimento científico e tecnológico, a
natureza e importância da tecnologia, seus alcances e limitações. A propriedade ou inadequação de certas práticas e processos industriais deverão ser analisadas pelos alunos (KRASILCHIK, 1987, p. 67).

Assim, percebemos que antes mesmo de surgirem os primeiros trabalhos com a denominação CTS no ensino de Ciências no Brasil, ideias bastante familiares a essa abordagem já eram defendidas por Krasilchik (1987). A mesma autora publica, vinte anos mais tarde, um livro (KRASILCHIK; MARANDINO, 2007) dedicado especificamente à ciência para cidadania, em que discutem vários aspectos da importância de se trabalhar as relações entre ciência, tecnologia e sociedade, em prol da alfabetização científica dos cidadãos. Veremos em seguida que, nesse momento, o movimento CTS na educação científica já é bastante popular entre os pesquisadores da área no contexto brasileiro.

É a partir do início deste século que a produção da área aumenta significativamente, com a publicação de artigos que de alguma forma abordam o movimento CTS na educação científica. Os primeiros anos da década passada constituem um período muito produtivo, em que artigos que hoje servem de referência para pesquisadores da área foram publicados em diversas revistas importantes. Dentre esses trabalhos destacamos Auler e Bazzo $(2001)^{4}$ e Santos e Mortimer (2002), que trazem importantes reflexões sobre a implementação do movimento CTS no contexto educacional brasileiro, Angotti, Bastos e Mion (2001), que trazem resultados de um proposta de discussão das relações entre ciência, tecnologia e sociedade em aulas de Física, Amorim (2001)5, que procura analisar os processos de produção de conhecimento escolar em aulas de Biologia nas quais um professor trabalha temáticas dentro do contexto das relações entre ciência, tecnologia e sociedade, entre outros.

Com relação à disseminação e extensão das pesquisas em Educação CTS, Araújo et. al. (2009) fazem um interessante levantamento em trabalhos apresentados nos principais eventos brasileiros da área no período entre 2003 e 2006. As autoras observam que

"os trabalhos publicados no período de 2003 e 2006, nos diversos eventos, [...] parecem, num primeiro momento, expressar timidamente o enfoque CTS,

\footnotetext{
4 Esses autores são os mais citados em trabalhos CTS publicados em anais de eventos ocorridos entre 2003 e 2006 (ARAÚJO; et. al., 2009). 5 Há outros artigos em que o autor aborda as relações CTS publicados anteriormente, como por exemplo: AMORIN, A. C. R. Biologia, Tecnologia e Inovação no Currículo do Ensino Médio. Investigações em Ensino de Ciências. V3(1), pp. 61-80, 1998.
} 
divulgado no Brasil, enquanto os primeiros trabalhos internacionais remontam à década de 1960" (ARAÚjo, et. al., 2009, p. 5)

Apesar desta constatação inicial, as autoras reconhecem que "a distribuição dos trabalhos nos eventos vem aumentando consideravelmente ao longo dos anos, independente da área do conhecimento" (ARAÚJO, et. al., 2009, p. 5). De fato a produção cresceu, como apontam Santos e Auler (2011), tendo em vista o "grande número de trabalhos brasileiros apresentados no ॥ Seminário Ibero-Americano Ciência-Tecnologia-Sociedade no Ensino de Ciências (II SIACTS), ocorrido em Julho de 2010, em Brasília" (SANTOS; AULER, 2011, p. 11).

Certamente muitos outros trabalhos mereciam ser aqui citados, por sua relevância e contribuição à Educação CTS no Brasil. Porém, não é nosso objetivo fazer um levantamento de toda a produção brasileira, mas sim trazer algumas contribuições de pesquisadores para refletir sobre a trajetória da pesquisa referente à essa temática no ensino de Ciências no contexto brasileiro desde a década de 1980.

A grande questão que levantamos, a essa altura, é: quanto tempo ainda vai levar para essa tendência incorporar efetivamente o cotidiano da sala de aula? Apesar de alguns autores apontarem documentos curriculares oficiais que contemplam elementos da perspectiva CTS(SANTOS; MORTIMER, 2002), além de vários estudos apontarem a presença desses pressupostos em documentos nacionais como os PCN, PCNEM ou OCNEM ${ }^{6}$ (ARAÚJO, et. al., 2009), parece ainda haver grande distância entre o âmbito acadêmico e a realidade escolar.

Essa preocupação pode ser melhor compreendida a partir da leitura do trabalho recentemente apresentado por Roehrig e Camargo (2011) no VIII ENPEC/ I CIEC ${ }^{7}$, que aborda como as relações CTS estão presentes no contexto do ensino público do Estado do Paraná, no que condiz ao documento curricular oficial, conhecimento dos professores sobre a temática e formação continuada oferecida aos docentes que atuam na disciplina de Física. Os resultados preliminares apontam que o trabalho sob o enfoque CTS não é promovido na instância curricular, na formação continuada e na prática docente escolar, no contexto da escola pública paranaense; resultados mais precisos serão obtidos em breve ${ }^{8}$, ao concluirmos a pesquisa.

\footnotetext{
${ }^{6}$ PCN: Parâmetros Curriculares Nacionais; PCNEM: Parâmetros Curriculares Nacionais - Ensino Médio; OCNEM: Orientações Curriculares Nacionais - Ensino Médio.

7 O VIII ENPEC (Encontro Nacional de Pesquisa em Educação em Ciências)/ I CIEC (Congreso Iberoamericano de Investigação em Enseñanza de las Ciencias) ocorreu em Campinas/SP, dezembro de 2011.

${ }^{8}$ A defesa da dissertação, cujo título provisório é A abordagem CTS nas diretrizes curriculares do Estado do Paraná, está prevista para fevereiro de 2013.
}

R. B. E. C. T., vol 6, núm. 2, mai-ago.2013 ISSN - 1982-873X 


\section{Considerações finais}

Inicialmente, buscou-se traçar um panorama das tendências para a Educação como um todo, a partir das ideias de Saviani (1994) e Libâneo (1983). É possível perceber as semelhanças entre as pedagogias propostas pelos autores - Crítico-Social dos Conteúdos e Histórico-Crítica pela preocupação que apresentam em relação à formação de um cidadão crítico. A pedagogia Histórico-Crítica é uma vertente presente em documentos curriculares desde o século passado, e há quem faça aproximações desta com a Educação CTS. No entanto, mesmo sendo uma corrente bem mais antiga no contexto brasileiro, o fato de ser uma tendência que dá muita ênfase aos conteúdos resulta que os professores das disciplinas científicas, por não saberem como trabalhar efetivamente sob esta concepção teórica, acabam perpetuando o método tradicional, seguindo a sequência dos conteúdos de acordo com os livros didáticos.

Tendências que são mais específicas ao Ensino de Ciências são destacadas por alguns autores, e percebemos que, até o final do século passado, trabalhos que abordam as relações CTS são bastante raros no âmbito da pesquisa da área no Brasil. Há, no entanto uma referência que remonta a década de 1980, na obra de Krasilchik (1987). Parece que a tendência apontada pela autora levou ainda um tempo para ser considerada, de modo que somente nos últimos anos da década seguinte começam a surgir trabalhos que estudam as relações CTS na educação científica. A partir do ano 2000 a quantidade de trabalhos que de alguma forma abordam a Educação CTS aumentou significativamente, o que pode vir a configurá-la como uma tendência de pesquisa em ascensão no contexto acadêmico brasileiro da área de Ensino de Ciências.

São aproximadamente dez anos de trabalhos produzidos no Brasil e cerca de quarenta anos de pesquisa em países europeus e EUA. Com relação a esse atraso, alguns autores defendem ser devido ao recente estabelecimento da democracia no Brasil, o que configura uma realidade bastante antiga nos países de primeiro mundo. No entanto, acredito que há outros fatores que influenciam a não consolidação da Educação CTS em nosso país, o que resulta em um grande distanciamento entre as produções acadêmicas e a sala de aula. A democracia já é uma realidade no Brasil a mais de duas décadas, consequentemente a educação de um modo mais amplo e a educação científica de maneira mais específica já deveriam ter incorporado as questões relacionadas às relações CTS, a fim de formar cidadãos que realmente possam opinar acerca de problemas que dizem respeito à sociedade em que vivem.

Creio que o que falta é um maior comprometimento dos organismos governamentais regionais, no âmbito estadual, em proporcionar capacitação a partir de cursos ou oficinas para os professores das disciplinas científicas, que abordem especificamente o trabalho com as relações CTS em sala de aula. Não posso afirmar categoricamente se isso é ou não uma realidade em outras regiões do Brasil, mas posso dizer com certeza que o Estado do Paraná não possui programas de formação continuada para professores das disciplinas científicas que abordem essas relações. Os cursos e oficinas ofertados abordam algumas novidades tecnológicas ou ideias 
de como fazer experimentos a partir de conteúdos, mas não se toca no assunto de como trabalhar aquele conhecimento e suas relações com a tecnologia e a sociedade, de modo que os alunos consigam enxergar a relação dos conceitos com a sua realidade e qual a importância daquilo no seu cotidiano.

Enfim, a Educação CTS configura uma tendência bastante promissora, pois parece ser uma perspectiva que realmente pode ajudar a mudar a visão deformada que se tem da ciência, bem como pode oferecer reais possibilidades de alfabetização científica dos cidadãos. Concordo com Martins e Paixão (2011), quando afirmam que

$$
\begin{aligned}
& \text { [...] o ensino CTS abandona os modelos transmissivos, os modelos de } \\
& \text { descoberta ou, ainda, os modelos internalistas de mudança conceptual para } \\
& \text { assentar numa perspectiva construtivista de cariz social que prima pela decisão } \\
& \text { consciente de preparar os alunos para assumirem um papel mais dinâmico e } \\
& \text { ativo na sociedade. (MARTINS; PAIXÃO, 2011, p. 147). }
\end{aligned}
$$

Acreditamos que esse construtivismo de cunho social é diferente do construtivismo que prioriza determinados conteúdos específicos, predominante nas duas últimas décadas do século passado, como apontam Carvalho e Vanucchi (1996). De qualquer forma, é preciso investir na disseminação dessas tendências entre os profissionais docentes que atuam no ensino básico, para que tenham condições de produzir um trabalho de qualidade, com embasamento teórico e vivência de práticas que envolvem o trabalho com as relações entre ciência, tecnologia e sociedade.

\section{Referências}

AIKENHEAD, Glen. What is STS science teaching? In: SOLOMON, Joan; AIKENHEAD, Glen. STS Education: international perspectives on reform. New York: Teachers College Press, 1994. p. 4759.

AMORIM, Antonio Carlos Rodrigues de. O que foge do olhar das reformas curriculares: nas aulas de Biologia, o professor como escritor das relações entre ciência, tecnologia e sociedade. Ciência \& Educação, Bauru, v. 7, n. 1, p.47-65, 2001.

ANGOTTI, José André Perez; BASTOS, Fábio da Purificação; MION, Rejane Aurora. Educação em Física: discutindo ciência, tecnologia e sociedade. Ciência \& Educação, Bauru, v. 7, n. 2, p.183-197, 2001.

ARAÚJO, Maria Cristina Pansera de; et al. Enfoque CTS na pesquisa em educação em ciências: extensão e disseminação. Revista Brasileira de Pesquisa em Educação em Ciências, Belo Horizonte, v. 9, n. 3, p.1-21, 2009. 
AULER, Décio. Novos caminhos para a educação CTS: ampliando a participação. In: SANTOS, Wildson Luiz Pereira; AULER, Décio. CTS e educação científica: desafios, tendências e resultados de pesquisa. Brasília: Editora Universidade de Brasília, 2011. p. 73-98.

AULER, Décio; BAZZO, Walter Antonio. Reflexões para implementação do movimento CTS no contexto educacional brasileiro. Ciência \& Educação, Bauru, v. 7, n. 1, p.1-13, 2001.

CARVALHO, Anna Maria Pessoa de; VANNUCCHI, Andréa. O currículo de Física: inovações e tendências nos anos noventa. Investigações em Ensino de Ciências, Porto Alegre, v. 1, n. 1, p.3-19, 1996.

KRASILCHIK, Myriam. O professor e o currículo das ciências. São Paulo: E. P. U., 1987.

KRASILCHIK, Myriam; MARANDINO, Martha. Ensino de ciências e cidadania. 2. ed. São Paulo: Moderna, 2007.

LIBÂNEO, Luiz Carlos. Tendências pedagógicas na prática escolar. Revista da Associação Nacional de Educação, São Paulo, v. 3, n. 3, p.11-19, 1983.

MARTINS, Isabel P.; PAIXÃO, Maria de Fátima. Perspectivas atuais Ciência-Tecnologia-Sociedade no ensino e na investigação em educação em ciências. In: SANTOS, Wildson Luiz Pereira; AULER, Décio (org.). CTS e educação científica: desafios, tendências e resultados de pesquisa. Brasília: Editora Universidade de Brasília, 2011. p. 135-160.

MESSORES, Claudia Maria. Um estudo sobre a educação em ciência, tecnologia e sociedade - CTS na ciências naturais das séries iniciais do ensino fundamental no contexto da proposta curricular de Santa Catarina - PC/SC. 104 f. Dissertação (Mestrado) - Departamento de Pós Graduação em Educação Científica e Tecnológica, Universidade Federal de Santa Catarina, Florianópolis, 2009. MOREIRA, Marco Antonio. Ensino de Física no Brasil: retrospectiva e perspectivas. Revista Brasileira de Ensino de Física, Porto Alegre, v. 22, n. 1, p.94-99, mar. 2000.

ROEHRIG, Silmara Alessi Guebur; CAMARGO, Sérgio. Estudando o movimento CTS no contexto curricular da disciplina de Física no Estado do Paraná. In: VIII ENCONTRO NACIONAL DE PESQUISA EM EDUCAÇÃO EM CIÊNCIAS, 2011, Campinas. Anais do VIII ENPEC - Encontro Nacional de Pesquisa em Educação em Ciências. Campinas: ABRAPEC, 2012. p. x - xx. Disponível em: <http://www.nutes.ufrj.br/abrapec/anais.html>. Acesso em: (aguardando publicação) SANTOS, Maria Eduarda Vaz Moniz Dos. A cidadania na "voz" dos manuais escolares: o que temos? O que queremos?. Lisboa: Horizonte, 2001.

SANTOS, Wildson Luiz Pereira. Significados da educação científica com enfoque CTS. In: SANTOS, Wildson Luiz Pereira; AULER, Décio. CTS e educação científica: desafios, tendências e resultados de pesquisa. Brasília: Editora Universidade de Brasília, 2011. p. 21-47. 
SANTOS, Wildson Luiz Pereira; AULER, Décio. CTS e educação científica: desafios, tendências e resultados de pesquisa. Brasília: Editora Universidade de Brasília, 2011.

SANTOS, Wildson Luiz Pereira; MORTIMER, Eduardo Fleury. Uma análise de pressupostos teóricos da abordagem C-T-S (Ciência-Tecnologia-Sociedade) no contexto da educação brasileira. Ensaio Pesquisa em Educação em Ciências, Belo Horizonte, v. 2, n. 2, p.1-23, dez. 2002.

SAVIANI, Demerval. Escola e Democracia: teorias da educação, curvatura da vara, onze teses sobre educação política. Campinas: Mercado Das Letras, 1994.

SOLOMON, Joan; AIKENHEAD, Glen. STS Education: international perspectives on reform. New York: Teachers College Press, 1994.

TEIXEIRA, Paulo Marcelo Marini. Educação científica e movimento CTS no quadro das tendências pedagógicas no Brasil. Revista Brasileira de Pesquisa em Educação em Ciências, Belo Horizonte, v. 3, n. 1, p.88-102, 2003.

YAGER, Robert Eugene. Science/Technology/Society as a reform in science education. Albany: State University Of New York Press, 1996.

ZIMAN, John. Teaching and learning about science and society. Cambridge: Cambridge University Press, 1980.

Silmara Alessi Guebur Roehrig - UFPR - Programa de Pós Graduação em Educação em Ciência e em Matemática - Setor de Ciências Exatas - sguebur@yahoo.com.br

Sérgio Camargo - UFPR - Departamento de Teoria e Prática de Ensino - Setor de Educação Curitiba - Paraná - s.camargo@ufpr.br 